\title{
Pharyngeal Anastomotic Leak, CTCAE
}

National Cancer Institute

\section{Source}

National Cancer Institute. Pharyngeal Anastomotic Leak, CTCAE. NCI Thesaurus. Code C143755.

A finding of leakage due to breakdown of a pharyngeal anastomosis (surgical connection of two separate anatomic structures). 